University of Nebraska - Lincoln

DigitalCommons@University of Nebraska - Lincoln

USDA National Wildlife Research Center - Staff Publications
U.S. Department of Agriculture: Animal and Plant Health Inspection Service

2010

\title{
Prey-mediated avoidance of an intraguild predator by its intraguild prey
}

Ryan R. Wilson

Utah State University, ryan.wilson@aggiemail.usu.edu

Terry L. Blankenship

Welder Wildlife Foundation, tblankenship@welderwildlife.org

Mevin B. Hooten

Utah State University, Mevin.Hooten@colostate.edu

John Shivik

USDA Wildlife Services NWRC, Logan UT, john.shivik@aphis.usda.gov

Follow this and additional works at: https://digitalcommons.unl.edu/icwdm_usdanwrc

Wilson, Ryan R.; Blankenship, Terry L.; Hooten, Mevin B.; and Shivik, John, "Prey-mediated avoidance of an intraguild predator by its intraguild prey" (2010). USDA National Wildlife Research Center - Staff

Publications. 1285.

https://digitalcommons.unl.edu/icwdm_usdanwrc/1285

This Article is brought to you for free and open access by the U.S. Department of Agriculture: Animal and Plant Health Inspection Service at DigitalCommons@University of Nebraska - Lincoln. It has been accepted for inclusion in USDA National Wildlife Research Center - Staff Publications by an authorized administrator of DigitalCommons@University of Nebraska - Lincoln. 


\title{
Prey-mediated avoidance of an intraguild predator by its intraguild prey
}

\author{
Ryan R. Wilson - Terry L. Blankenship · \\ Mevin B. Hooten · John A. Shivik
}

Received: 29 June 2010 / Accepted: 16 September 2010 / Published online: 16 October 2010

(C) Springer-Verlag 2010

\begin{abstract}
Intraguild (IG) predation is an important factor influencing community structure, yet factors allowing coexistence of IG predator and IG prey are not well understood. The existence of spatial refuges for IG prey has recently been noted for their importance in allowing coexistence. However, reduction in basal prey availability might lead IG prey to leave spatial refuges for greater access to prey, leading to increased IG predation and fewer opportunities for coexistence. We determined how the availability of prey
\end{abstract}

Communicated by Janne Sundell.

\section{R. R. Wilson}

Department of Wildland Resources,

Utah State University, Logan, UT 84322, USA

T. L. Blankenship

Welder Wildlife Foundation,

P.O. Box 1400, Sinton, TX 78387, USA

M. B. Hooten

Department of Mathematics and Statistics,

Utah State University, Logan, UT 84322, USA

J. A. Shivik

USDA Wildlife Services National Wildlife Research Center,

Utah State University, Logan, UT 84322, USA

Present Address:

R. R. Wilson $(\varangle)$

The Wilderness Society, 705 Christensen Dr.,

Anchorage, AK 99501, USA

e-mail: ryan.wilson@aggiemail.usu.edu

Present Address:

M. B. Hooten

USGS Colorado Cooperative Fish and Wildlife Research Unit, Department of Fish, Wildlife, and Conservation Biology,

Colorado State University, 201 JVK Wagar Bldg,

Fort Collins, CO 80523, USA affected space-use patterns of bobcats (Lynx rufus, IG prey) in relation to coyote space-use patterns (Canis latrans, IG predators). We located animals from fall 2007 to spring 2009 and estimated bobcat home ranges and core areas seasonally. For each bobcat relocation, we determined intensity of coyote use, distance to water, small mammal biomass, and mean small mammal biomass of the home range during the season the location was collected. We built generalized linear mixed models and used Akaike Information Criteria to determine which factors best predicted bobcat space use. Coyote intensity was a primary determinant of bobcat core area location. In bobcat home ranges with abundant prey, core areas occurred where coyote use was low, but shifted to areas intensively used by coyotes when prey declined. High spatial variability in basal prey abundance allowed some bobcats to avoid coyotes while at the same time others were forced into more risky areas. Our results suggest that multiple behavioral strategies associated with spatial variation in basal prey abundance likely allow IG prey and IG predators to coexist.

Keywords Bobcat $\cdot$ Coexistence $\cdot$ Coyote $\cdot$ Intraguild predation $\cdot$ Spatial refuge

\section{Introduction}

Intraguild (IG) predation is increasingly recognized as an important factor influencing community structure (Crooks and Soulé 1999; Berger and Gese 2007). Models suggest that IG predation should be rare (Holt and Polis 1997; Mylius et al. 2001), yet it is frequently documented in natural systems (Palomares and Caro 1999; Donadio and Buskirk 2006). However, these models fail to account for individual antipredator behavior that could lead to 
additional scenarios where coexistence can occur (Heithaus 2001; Janssen et al. 2007). Numerous studies have recently shown the importance of avoidance behavior by IG prey towards IG predators for their coexistence (Heithaus 2001; Janssen et al. 2007; Choh et al. 2010). Avoidance can be through the use of spatial refuges by IG prey where IG predators are rare (e.g., Durant 1998), by occupying areas with greater structural complexity, thereby allowing for reduced detectability or enhanced ability to escape detection by IG predators (Janssen et al. 2007), or by temporally avoiding IG predators when they are most active by shifting activity patterns (e.g., Arjo and Pletscher 1999).

While many IG prey species show a preference for areas with reduced probabilities of encountering IG predators (Durant 1998; Sergio et al. 2003; Choh et al. 2010), this often comes at the cost of reduced access to prey (Mills and Gorman 1997; Durant 1998; Heithaus 2001; Thompson and Gese 2007). Thus, IG prey face a tradeoff between access to sufficient prey and avoiding areas with high probabilities of encountering IG predators, just as prey in "traditional" predator-prey relationships (Lima and Dill 1990). In "traditional" predator-prey studies, prey increase their risk of exposure to predators in order to access areas with greater resource abundance when resources are low (e.g., Pettersson and Brömark 1993; Whitham and Mathis 2004).

Few studies have investigated similar relationships between IG predator and IG prey, but there is some evidence that IG prey increase exposure to IG predators when prey is low (Polis et al. 1989; Palomares and Caro 1999; Sergio et al. 2003), or when thermal conditions are suboptimal (Webb et al. 2009). Given that the likelihood of encountering IG predators is probably a main factor leading to IG predation (Moehrenschlager et al. 2007), any factor that increases the probability of encounter might reduce the potential for coexistence. Additionally, IG prey are only predicted to use areas of low productivity when overall levels of basal prey are high (Heithaus 2001). Thus, if overall levels of prey decline, IG prey may be forced into riskier areas, possibly leading to increased IG predation. We therefore studied how the availability of basal prey affected space-use patterns of IG prey in relation to the probability of encountering IG predators. We predicted that as basal prey abundance declined, IG prey would increase their exposure to IG predators in order to access areas with more abundant basal prey.

Specifically, we studied the spatial relationships between bobcats (Lynx rufus, IG prey) and coyotes (Canis latrans, IG predator) in relation to changes in the abundance of small mammals which represent the primary prey of bobcats (Blankenship 2000).

Bobcats and coyotes exhibit a clear IG predator-prey relationship, with numerous accounts of bobcats being killed by coyotes (Knick 1990; Fedriani et al. 2000; Gipson and Kamler 2002; T.L. Blankenship unpublished data) and bobcats avoiding coyotes at the core area scale (Neale and Sacks 2001; Thornton et al. 2004). Additionally, bobcat populations respond positively to reductions in sympatric coyote population (Henke and Bryant 1999). Bobcat spaceuse patterns are also strongly influenced by prey abundance, with bobcats ranging much more widely during periods of low prey abundance (Knick 1990; Blankenship 2000).

\section{Materials and methods}

\section{Study area}

Our study occurred on the Welder Wildlife Foundation Refuge (approx. 3,150 ha), located approximately $10 \mathrm{~km}$ north of Sinton, Texas. The study area was located in a transition zone between the gulf prairies and marshes and south Texas plains, and vegetation consisted mainly of mixed grasslands and shrubs (Young et al. 2006).

Coyote territories form a continuous patchwork across the refuge, with approximately seven to eight territories always present and exhibiting high spatial stability through time (Young et al. 2006). Pack sizes range between three and seven adults (Andelt 1985). Bobcats are less abundant on the refuge (approx. 15, Heilbrun et al. 2006), but show extensive home range overlap with coyote territories.

The dietary overlap of coyotes and bobcats is low except for the common use of small mammals. Coyotes tend to have more varied diets, with fruit making up a considerable portion of their diet at many times during the year (Young et al. 2006). Additionally, larger mammals [e.g., whitetail deer (Odocoileus virginianus) and feral pigs (Sus scrofa)] are a more common constituent of coyote diets (Young et al. 2006) than bobcat diets (Blankenship 2000). The preferred prey of bobcats on the refuge were cotton rats (Sigmodon hispidus), wood rats (Neotoma micropus), and eastern cottontails (Sylvilagus floridanus, Blankenship 2000). However, bobcats switch to a greater proportion of birds (both passerine and waterfowl) during periods of low small mammal abundance (Blankenship 2000).

\section{Bobcat and coyote monitoring}

Bobcats were captured using modified Tomahawk live traps (Tomahawk Live Trap Co, Tomahawk, WI; $107 \times 38 \times 51 \mathrm{~cm})$. An extension $(51 \times 38 \times 51 \mathrm{~cm})$ was added to the trap to house and protect live chickens used as bait (Blankenship 2000). We immobilized captured bobcats with an intramuscular injection of ketamine (i.e., $10-15 \mathrm{mg} / \mathrm{kg}$ body mass) and acepromazine (i.e., $0.05 \mathrm{mg} / \mathrm{kg}$ body mass). Coyotes were captured using padded leg hold traps 
(Victor \#3; Softcatch, Lititz, PA), neck snares, or collarums (Wildlife Control Supplies, East Granby, CT). Captured coyotes were not chemically immobilized. Both bobcats and coyotes were fitted with VHF collars (bobcats: Advanced Telemetry Systems, Isanti, MN; coyotes: Lotek, Newmarket, ON, Canada). All captures occurred between April 2007 and November 2008.

We obtained relocations on each bobcat and coyote 4-5 days per week using triangulation and the maximum likelihood estimator in program Locate II (Nams 2006) to estimate animal locations. Locations were estimated using $\geq 3$ bearings collected within 20 min, between 20 and $160^{\circ}$ of each other. Mean distance between the estimated and true locations was $260 \mathrm{~m}$ [standard deviation (SD) 215]. We randomly chose start times and animals for telemetry sessions to ensure the data were not autocorrelated (Fieberg 2007). Both diurnal and nocturnal locations for bobcats and coyotes were collected.

\section{Home range analysis}

The home ranges of individual bobcats were estimated on the basis of $\geq 30$ locations to ensure that we obtained a sufficient number of relocations to estimate home ranges (Seaman et al. 1999). We used the fixed kernel method (Worton 1989) with the ad hoc bandwidth selection procedure (see Berger and Gese 2007). In this study, the home range was defined as the area encompassed by the $95 \%$ isopleth. To estimate bobcat core areas, we analyzed home ranges for clusters of locations and used Bayesian methods to identify which isopleth partitioned the home range into homogeneous point patterns (Wilson et al. 2010). This method is highly precise for characterizing points as occurring inside or outside the core area. We estimated bobcat home ranges and core areas for all relocation data (day and night combined, hereafter full core area), relocation data obtained during the day (0700-1900 hours, hereafter daytime core area), and relocation data obtained at night (1900-0700 hours, hereafter nighttime core area).

\section{Small mammal trapping}

We established 15-45 trapping grids from autumn (September-November) 2007 to spring (February-April) 2009, distributing trapping grids among all of the major vegetative communities on the study area (Blankenship 2000). Each trapping grid consisted of 25 Sherman live traps (H.B. Sherman Traps, Tallahassee, FL) baited with grain (cornmilo mixture), in a $5 \times 5$ design, with traps spaced $10 \mathrm{~m}$ apart. We opened traps in each grid for three nights and captured small mammals were individually marked by trimming guard hairs in a unique design. Each grid was only sampled once (i.e., open for three nights) each season.
For each grid, we determined the total biomass of all small mammals captured based on average weights found on the study site (Otteni et al. 1972). This is similar to the approach taken by Randa et al. (2009). The number of trapping grids sampled differed each season because of differing levels of field assistance and because weather conditions sometimes hindered our ability to sample a trapping grid each season.

\section{Data analysis}

We created kernel intensity maps (Schabenberger and Gotway 2005) of coyote space use based on those territories which had $>30$ points for a respective season. If multiple coyotes resided in the same territory, we combined their relocations. We created a $100 \times 100-\mathrm{m}$ grid across the study area, and for each coyote territory, and estimated the kernel density (with ad hoc bandwidth) value at each grid cell using the function ' $k d e 2 d$ ' in the MASS library (Venable and Ripley 2002) in the R Statistical Computing Environment (R Development Core Team 2008). We then extracted the grid cells that fell within the $95 \%$ isopleth of each coyote territory and scaled each territory's grid cell values to their respective mean value in order to control for interterritorial differences in the number of relocations used for kernel density estimates. If grid cells contained multiple intensity estimates (i.e., the grid cell was contained within multiple territories), we only used the greatest intensity value. We created coyote intensity grids based on day, night, and day and night combined coyote relocations for each season.

A statistical approach was used to spatially predict small mammal biomass across the study area each season and at each observed bobcat location. Our trapping data were zero-inflated (i.e., many grids with no captures); consequently, we were unable to use standard optimal spatial prediction methods (e.g., kriging equations). Instead, we used a hurdle model (e.g., Ver Hoef and Jansen 2007) for the correlated zero process (i.e., locations with no captures) and then a correlated log-Gaussian model at locations with captures. This is essentially a mixture model similar to a zero-inflated model, except that a value of zero can only come from one component of the mixture, rather than two. We used an exponential covariance structure on both the zero and positive processes.

After obtaining spatial prediction maps of small mammal biomass, it was clear that certain regions of the study area had higher overall prey biomass than others (Fig. 1). Given that the availability of prey can influence the level of risk an animal takes while foraging (e.g., Cooper 2000), we determined the mean small mammal biomass in each bobcat's home range for each season as an index of home range quality. Whereas the predicted values of small mammal 

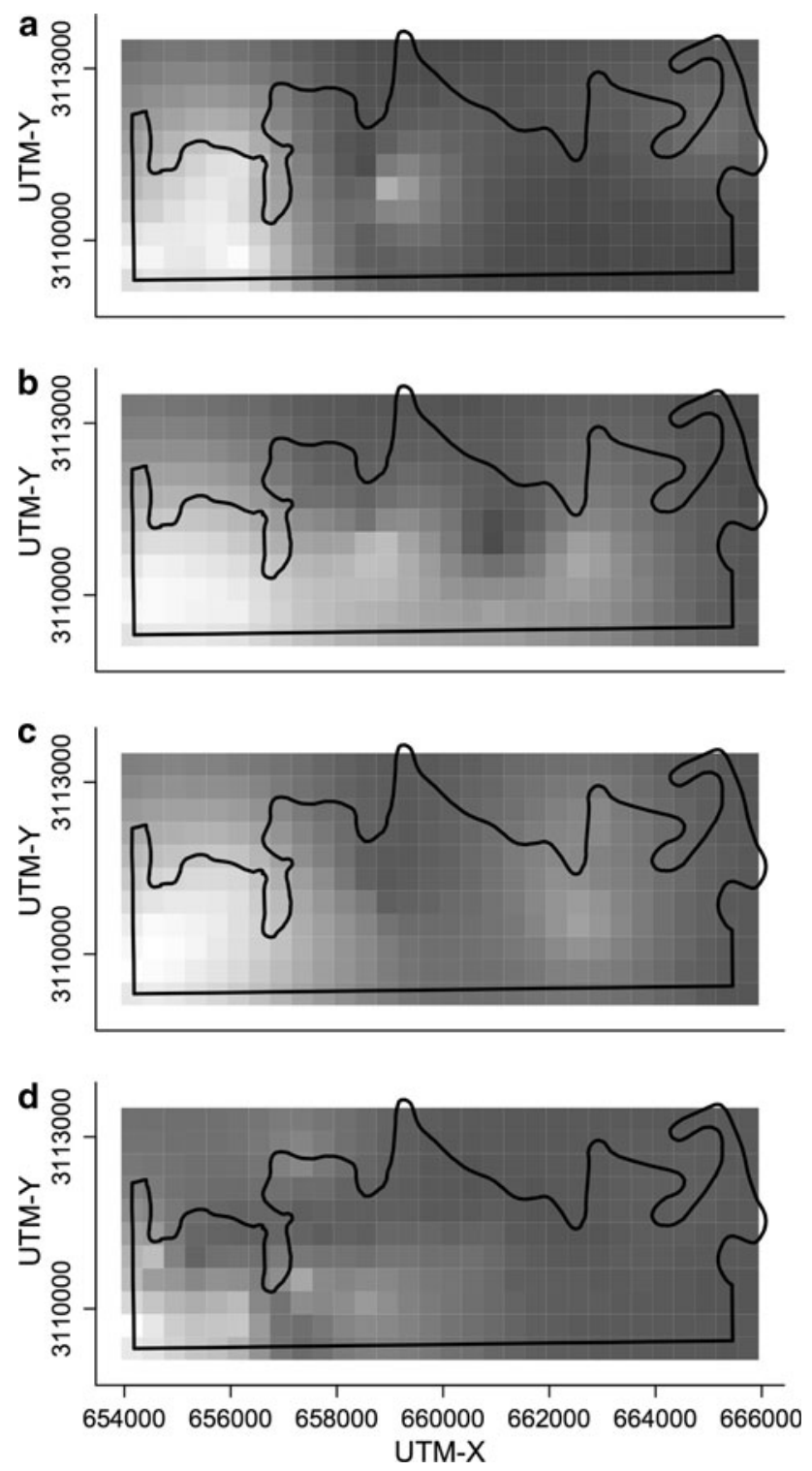

Fig. 1 Predictive map of small mammal biomass obtained with a hurdle model across the study area in autumn 2007 (a), spring 2008 (b), autumn 2008 (a), and spring 2009 (a). Trapping occurred between February and May for spring and between August and November for autumn. Predicted small mammal biomass ranged from 4 (black) to $2,019 \mathrm{~g}$ (white). The black outline represents the Welder wildlife refuge, Sinton, Texas boundary

biomass at each bobcat relocation provide information about the spatial distribution of resources at the home range scale, the mean home range biomass (i.e., home range quality) provides a measure of relative prey availability for each bobcat at the study site scale.

For each bobcat relocation, we determined small mammal biomass, intensity of coyote use, and the mean small mammal biomass of the home range where the point occurred. We also determined the distance to water because of the importance of water birds in bobcat diets in the study area during periods of low small mammal abundance
(Blankenship 2000). We used the estimated home range and core areas for each bobcat during each season to determine whether a relocation occurred inside or outside the core area (coded as 1 or 0 , respectively). We used the distance to water, coyote space-use intensity, and small mammal biomass as variables and all two-way interactions with mean home range and small mammal biomass for model selection. We also had repeated measures on individuals; thus, we used a logistic generalized linear mixed model [function 'Imer' in R package 'Ime4' (Bates 2007)] with bobcat as a random factor to determine which explanatory variables best explained whether a relocation was from inside or outside its core area (Zuur et al. 2009). We standardized all variables prior to analysis (Zuur et al. 2009) and used Akaike Information Criteria (AIC, Burnham and Anderson 1998) to determine the most parsimonious model that best fit the observed data. We used the same procedure to determine the best fitting models for day relocations, night relocations, and day and night relocations combined.

\section{Results}

We captured seven bobcats ( 5 males, 2 females) and 13 coyotes ( 8 males, 5 females), with each having a portion of its home range overlapping with the opposite species' home range. The 13 captured coyotes resided in seven distinct territories on the refuge. We obtained 1,201 bobcat locations that overlapped with $\geq 1$ coyote territory for bobcat home ranges estimated with day and night locations over all seasons and individuals. Of those locations, 680 were classified as occurring inside core areas, and 521 outside. For daytime bobcat home ranges, we obtained 348 (227 inside, and 121 outside core areas) bobcat locations that overlapped with coyote daytime territory estimates. For nighttime bobcat home ranges, 334 (197 inside, and 137 outside core areas) bobcat locations overlapped with coyote nighttime territory estimates. For day and night combined, individual bobcats had $66.7 \pm 5.9$ [mean \pm standard error (SE)] locations that overlapped with estimated coyote territories each season $(37.8 \pm 3.7$ and $28.9 \pm 4.0$ from inside and outside of core areas, respectively). For daytime bobcat home ranges, there were $31.6 \pm 4.4$ locations for individual bobcats used for analysis each season $(20.6 \pm 3.8$, and $11.0 \pm 2.2$, from inside and outside of core areas, respectively). Finally, for nighttime bobcat home ranges, there were $27.8 \pm 4.1$ locations for individual bobcats used for analysis each season $(16.4 \pm 3.0$, and $11.4 \pm 2.1$, from inside and outside of core areas, respectively). Mean small mammal biomass in bobcat home ranges varied from 6.5 to $1,199 \mathrm{~g}$.

The top-ranked model for the full bobcat core area included intensity of coyote use and distance to water, each 
Table 1 Results of Akaike Information Criteria analysis for the top ten of 27 candidate logistic generalized linear mixed models with the individual as a random effect explaining the location of core areas within bobcat home ranges based on day and night relocations combined $(n=1,201)$

\begin{tabular}{|c|c|c|c|c|}
\hline Model & AIC & $\Delta \mathrm{AIC}$ & $k$ & $w_{\mathrm{i}}$ \\
\hline Coy, D2W, HRQ, Coy $\times$ HRQ, D2W $\times$ HRQ & 1,617 & 0 & 7 & 0.535 \\
\hline SmMam, Coy, D2W, HRQ, Coy $\times$ HRQ, D2W $\times$ HRQ & 1,619 & 2 & 8 & 0.197 \\
\hline SmMam, Coy, D2W, HRQ, SmMam $\times$ HRQ, Coy $\times$ HRQ, D2W $\times$ HRQ & 1,621 & 4 & 9 & 0.072 \\
\hline $\mathrm{D} 2 \mathrm{~W}, \mathrm{HRQ}, \mathrm{D} 2 \mathrm{~W} \times \mathrm{HRQ}$ & 1,621 & 4 & 5 & 0.072 \\
\hline Coy, D2W, HRQ, D2W × HRQ & 1,622 & 5 & 6 & 0.044 \\
\hline SmMam, D2W, HRQ, D2W × HRQ & 1,623 & 6 & 6 & 0.027 \\
\hline Coy, SmMam, D2W, HRQ, D2W × HRQ & 1,623 & 6 & 7 & 0.027 \\
\hline SmMam, D2W, HRQ, SmMam $\times$ HRQ, D2W $\times$ HRQ & 1,624 & 7 & 7 & 0.016 \\
\hline SmMam, Coy, D2W, HRQ, SmMam $\times$ HRQ, D2W $\times$ HRQ & 1,625 & 8 & 8 & 0.010 \\
\hline SmMam, Coy, HRQ, SmMam $\times$ HRQ, Coy $\times$ HRQ & 1,637 & 20 & 7 & 0.000 \\
\hline
\end{tabular}

Variables for models included small mammal biomass (SmMam), coyote space use intensity (Coy), distance to water (D2W), home range quality (HRQ) and all two-way interactions with HRQ (denoted by $x$ )

AIC Akaike Information Criteria values, $\triangle A I C$ differences from the model with the lowest AIC value, $k$, number of parameters, $w_{\mathrm{I}}$, Akaike weights

Table 2 Regression coefficients of best fitting logistic generalized linear mixed models with individual as a random effect and assessed by AIC

\begin{tabular}{llrlr}
\hline Data & Variables & Coefficient & \multicolumn{1}{l}{ SE } & $P$ value \\
\hline Day + night & Intercept & 0.205 & 0.105 & 0.051 \\
& HRQ & -0.119 & 0.103 & 0.249 \\
& Coy & 0.060 & 0.062 & 0.336 \\
& Coy $\times$ HRQ & -0.165 & 0.063 & 0.009 \\
& D2W & 0.070 & 0.065 & 0.278 \\
Day & D2W $\times$ HRQ & 0.347 & 0.072 & $<0.001$ \\
& Intercept & 0.655 & 0.371 & 0.078 \\
& HRQ & 0.004 & 0.379 & 0.992 \\
& SmMam & -0.589 & 0.290 & 0.042 \\
& D2W & -0.420 & 0.164 & 0.010 \\
& D2W $\times$ HRQ & 0.360 & 0.155 & 0.020 \\
Coy & -0.007 & 0.164 & 0.968 \\
& Coy $\times$ HRQ & -0.499 & 0.196 & 0.011 \\
& Intercept & 0.344 & 0.242 & 0.155 \\
& HRQ & -0.231 & 0.222 & 0.298 \\
& Coy & 0.380 & 0.130 & 0.003 \\
& Coy $\times$ HRQ & -0.288 & 0.106 & 0.006 \\
& Hight & & &
\end{tabular}

Models are for bobcat home range and core area estimates based on day (day), night (night), and day and night relocations combined $($ day + night $)$

interacting with home range quality (Table 1 ). This model accounted for $53.5 \%$ of the Akaike weights (Table 1). The only other competing model (i.e., $\triangle \mathrm{AIC}<2$ ) included the small mammal biomass term, but the slope was not different from $0(P=0.60)$, and it only accounted for $19.7 \%$ of the Akaike weights (Table 1). Coefficient estimates for the top-ranked model (Table 2) indicated that as prey abun-

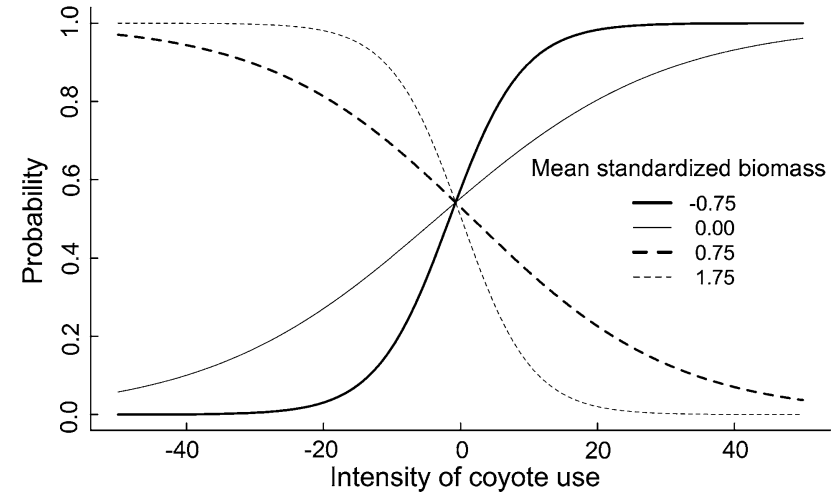

Fig. 2 Estimated logistic functions for the best fitting model for the full bobcat core area (i.e., day and night combined) with changes in standardized values of coyote space-use intensity and mean home range prey biomass. Other variables were held constant (e.g., distance to water, and its interaction with mean home range biomass)

dance increased in home ranges, core areas increasingly occurred further from water and had lower coyote use (Table 2; Fig. 2).

The top-ranked model for daytime core areas included the small mammal, coyote, and distance to water covariates, with home range quality interacting with coyote use and distance to water (Table 3). Coefficient estimates for this model indicated that bobcat core areas were negatively associated with small mammal biomass and occurred further from water and areas intensely used by coyotes with increasing home range quality (Table 2). There were two competing models, one which included the interaction between small mammal biomass and home range quality, and the other which excluded any small mammal biomass variables (Table 3). Coefficients for the model with the interaction between small mammal biomass and home 
Table 3 Results of Akaike Information Criteria analysis for the top ten of 27 candidate logistic generalized linear mixed models with individual as a random effect explaining the location of bobcat core areas within home ranges based on daytime relocations (i.e., 700-1900 hours, $n=348$ )

\begin{tabular}{|c|c|c|c|c|}
\hline Model & AIC & $\Delta \mathrm{AIC}$ & $k$ & $w_{\mathrm{i}}$ \\
\hline SmMam, Coy, D2W, HRQ, Coy $\times$ HRQ, D2W $\times$ HRQ & 408.4 & 0 & 8 & 0.359 \\
\hline SmMam, Coy, D2W, HRQ, SmMam $\times$ HRQ, Coy $\times$ HRQ, D2W $\times$ HRQ & 409.7 & 1.3 & 9 & 0.188 \\
\hline Coy, D2W, HRQ, Coy $\times$ HRQ, D2W $\times$ HRQ & 410.4 & 2 & 7 & 0.132 \\
\hline Coy, D2W, HRQ, Coy $\times$ HRQ & 410.8 & 2.4 & 6 & 0.108 \\
\hline SmMam, D2W, Coy, HRQ, Coy $\times$ HRQ & 411.6 & 3.2 & 7 & 0.073 \\
\hline SmMam, Coy, D2W, HRQ, SmMam $\times$ HRQ, Coy $\times$ HRQ & 413.6 & 5.2 & 8 & 0.027 \\
\hline SmMam, D2W, HRQ, D2W × HRQ & 413.7 & 5.3 & 6 & 0.025 \\
\hline SmMam, Coy, HRQ, Coy $\times$ HRQ & 414.4 & 6 & 6 & 0.018 \\
\hline SmMam, D2W, HRQ, SmMam $\times$ HRQ, D2W $\times$ HRQ & 414.7 & 6.3 & 7 & 0.015 \\
\hline Coy, HRQ, Coy $\times$ HRQ & 415.3 & 6.9 & 5 & 0.011 \\
\hline
\end{tabular}

range quality indicated that as home range quality increased, the probability of the daytime core area occurring in high prey areas decreased.

The top-ranked model for nighttime core areas only included the interaction between coyote intensity and home range quality (Table 4). Coefficient estimates indicated that as home range quality increased, core areas had an increased probability of occurring in areas with low coyote use (Table 2). There were two additional competing models, each of which contained the interaction between coyote and home range quality (Table 4). The second-ranked model contained the small mammal biomass covariate, indicating core areas occurred in areas of the home range with greater small mammal biomass. The third-ranked model contained the distance to water variable (Table 4), indicating core areas occurred further from water than areas outside the core area.

\section{Discussion}

Our results support the concept that the stability of IG predation in our system is most likely influenced by bobcats "safety matching" (Heithaus 2001) rather than outcompeting coyotes for shared resources-although bobcat safety matching is context-dependent. Bobcats tended to safety match when basal prey populations were high inside an individual's home range, but forewent safety matching when prey levels were low. If prey abundance were to be constant across the entire population, this could lead to an unstable system wherein during periods of low prey abundance, all bobcats would be forced to leave spatial refugia, increasing the probability of negative interactions with coyotes. An interesting result of our analysis, however, is that even within a population, prey abundance was found to vary spatially, allowing some individuals to continue safety matching while others were required to use riskier areas to access sufficient prey.

A key missing link in our understanding of IG predation is the identification of which factors affect the dynamics of IG predator-prey interactions (Polis et al. 1989; Palomares and Caro 1999; Donadio and Buskirk 2006; Gehrt and Prange 2007; Thompson and Gese 2007). Our results, however, suggest that the dynamics of IG predator-prey interactions generally follow the same rules as those for "traditional" predator-prey systems. Within predator-prey systems, there are areas where prey remain relatively invulnerable to predation (Matter and Mannan 2005) as a result of inaccessibility by predators or a high probability of escape (Creswell et al. 2010). The increased risk of preda-
Table 4 Results of Akaike Information Criteria analysis for the top ten of 27 candidate logistic generalized linear mixed models with individual as a random effect explaining the location of bobcat core areas within home ranges based on nighttime relocations (i.e., 1900-700 hours; $n=334$ )

\begin{tabular}{lllll}
\hline Model & AIC & AIC & $k$ & $w_{\text {i }}$ \\
\hline Coy, HRQ, Coy $\times$ HRQ & 437.1 & 0 & 5 & 0.381 \\
SmMam, Coy, HRQ, Coy $\times$ HRQ & 439.1 & 2 & 6 & 0.140 \\
D2W, Coy, HRQ, Coy $\times$ HRQ & 439.1 & 2 & 6 & 0.140 \\
Coy, D2W, HRQ, Coy $\times$ HRQ, D2W $\times$ HRQ & 440.8 & 3.7 & 7 & 0.060 \\
SmMam, Coy, HRQ, SmMam $\times$ HRQ, Coy $\times$ HRQ & 441 & 3.9 & 7 & 0.054 \\
SmMam, D2W, Coy, HRQ, Coy $\times$ HRQ & 441.1 & 4 & 7 & 0.052 \\
Coy & 441.7 & 4.6 & 3 & 0.038 \\
SmMam, Coy & 442.1 & 5 & 4 & 0.031 \\
SmMam, Coy, D2W, HRQ, Coy $\times$ HRQ, D2W $\times$ HRQ & 442.8 & 5.7 & 8 & 0.022 \\
SmMam, Coy, D2W, HRQ, SmMam $\times$ HRQ, Coy $\times$ HRQ & 443 & 5.9 & 8 & 0.020 \\
\hline
\end{tabular}


tion outside of these refuges can significantly restrict prey space use. For example, Heithaus and Dill (2002) showed that bottlenose dolphins (Tursiops aduncus) avoided highquality foraging areas when their predators, tiger sharks (Galeocerdo cuvier), were present, even at a relatively low density. Only when sharks were absent in the system would dolphins forage in those areas. Even though prey are capable of restricting use to areas with low predation risk, numerous studies have shown prey to take greater risks to acquire resources when other needs become more pressing, such as avoiding starvation (Sih 1992; Pettersson and Brömark 1993; Whitham and Mathis 2004; Creswell et al. 2010). Creswell et al. (2010) found that redshanks (Tringa tetanus) avoided areas with greater risk of predation from Eurasion sparrowhawks (Accipiter nisus) and subsequently avoided $>25 \%$ of their available habitat when temperatures were $>5^{\circ} \mathrm{C}$. However, when temperatures were $<5^{\circ} \mathrm{C}$ and the risk of starvation more imminent, redshanks increased their use of those risky areas. Thus, prey must constantly balance multiple risks and the need to find strategies to minimize those risks (Sih 1980).

Our results clearly show a similar pattern between IG predator-prey relationships. When basal prey was low within a home range, bobcats were forced to use riskier areas to meet their energetic needs. The importance of the interaction between home range quality and intensity of coyote use is further supported by the fact that models with the interaction accounted for $80-92 \%$ of the total AIC weights. Bobcats in high-quality home ranges are likely not food stressed and have access to sufficient prey; both factors allow them to restrict space use to areas with a lower risk of encountering coyotes. Webb et al. (2009) found a similar relationship with IG predator interactions in snakes: in their study, juvenile snakes of the IG prey species took greater risks of IG predation to use areas with favorable microclimates, whereas adults did not take those risks because of their greater thermal tolerance.

Bobcats are generally considered to be nocturnal (Neale and Sacks 2001), but our results suggest that when small mammal abundance decreases, bobcats increase their daytime activity to gain access to water birds when they are most active (Brisbin and Mowbray 2002). This shift in bobcat activity is further supported by the fact that the topranked nighttime core area models did not include distance to water as a covariate, or if it did, the model showed that core areas were located further from water. Our top daytime core area models also suggest that bobcats increased daytime foraging for small mammals when the latter were low in abundance, as indicated by a higher probability of core areas occurring where small mammal abundance was higher in the home range during periods of low prey abundance than during periods of high prey abundance. By having to forage during the day, bobcats likely increase their exposure to IG predation, especially because daytime core areas shift to areas with greater coyote use when prey abundance is low. Other normally nocturnal IG prey species have been shown to increase their daytime activity for increased access to food, even though exposure to IG predation increases (Sunde et al. 2003). While coyotes at the study site have been shown to be most active at night, they still are active at all other times of the day (Young et al. 2006), so temporal avoidance of bobcats towards coyotes seems unlikely.

The relationship we found between bobcats and coyotes is intriguing given the relative rarity of coyote predation on bobcats. Others have also shown that IG prey can exhibit a behavioral response towards IG predators, even though predation is rarely observed (Sergio et al. 2007; Zuberogoitia et al. 2008) and indirect predator effects can have an equal or greater effect on prey population (Creel and Christianson 2008) and community dynamics (Creswell et al. 2010). Bobcats on the study site have been found to react negatively to the perceived presence of coyotes: when presented with a coyote call playback at a relatively short distance (approx. $20 \mathrm{~m}$ ), a bobcat immediately ran for the closest dense vegetative cover R. Wilson, personal observation). While no bobcats were killed by coyotes during our study, during a previous study on the refuge, a bobcat was killed by a coyote, coinciding with a period of low prey abundance (T.L. Blankenship, unpublished data). The relatively rarity of IG predation suggests that the space-use strategy employed by bobcats is relatively effective at avoiding coyotes.

One assumption of our analysis is that uncollared bobcats and coyotes did not influence our results. This could be problematic, for instance, if uncollared coyotes intensively used space estimated as used infrequently by collared coyotes. We do not believe this is a problem, however, because we had $23-62 \%$ of the coyote population collared given the number of territories present on the refuge and average pack sizes (Andelt 1985). Because coyote space use on the refuge is relatively stable over time (Young et al. 2006) and because coyote movements within territories are typically highly correlated, space-use data obtained from collared coyotes should be representative of uncollared coyotes in the territory. An increase in the number of coyotes collared in a territory would only result in more precise estimates of use, but it would not influence the general pattern of intensity of use. Additionally, because coyote intensity maps were bounded by the estimated territory boundaries and we restricted our use of bobcats relocations to those that overlapped with those intensity maps, we reduce the likelihood of associating a location with an artificially low coyote use value. Given that we had approximately $50 \%$ of the bobcat population collared (approx. 15; Heilbrun et al. 2006) and that bobcats are solitary felids, the presence of uncollared bobcats likely had limited influence on our results. 
Finally, our results provide some insight into the underlying behaviors that lead to the development of bobcat core areas. Few studies have tested hypotheses on how animals use core areas (e.g., Barg et al. 2006), and most have assumed they represent foraging areas (Powell et al. 1997; Plowman et al. 2006). Our results indicate, however, that bobcat core area behavior is not just a function of prey abundance, but a balance between prey abundance and coyote avoidance. Spatial variation in basal prey abundance allowed individuals in the population to employ multiple behavioral strategies to deal with the coyote risk. Thus, at any given time, some bobcats remained relatively invulnerable to IG predation, while others increased the likelihood of encountering coyotes. These multiple behavioral strategies employed over such a small area likely enhance the potential for IG competitors to coexist. Future research should continue to focus on how local-scale heterogeneity might influence IG predation dynamics within a given community and use existing information on predatorprey dynamics to inform research on IG predator-prey dynamics.

Acknowledgments This research was funded by the Welder Wildlife Foundation, American Society of Mammalogists, and USDA Wildlife Services National Wildlife Research Center. We thank S.N. Glasscock for valuable discussion and the staff of the Welder Wildlife Foundation for support throughout. J. du Toit, E.M. Gese, J.A. Powell, and J.A. Bissonette, and two anonymous reviewers provided valuable comments on earlier versions of this manuscript. We thank P. Darrow, S. Meggers, C. Burnett, J. Williams, M. Bales, and O. Chan for assistance in data collection. This is Welder Wildlife Foundation Publication Number 962.

\section{References}

Andelt WF (1985) Behavioral ecology of coyotes in south Texas. Wildl Monogr 94:1-45

Arjo WM, Pletscher DH (1999) Behavioral responses of coyotes to wolf recolonization in northwestern Montana. Can J Zool 77:1919-1927. doi:10.1139/cjz-77-12-1919

Barg JJ, Aiama DM, Jones J, Robertson RJ (2006) Within-territory habitat use and microhabitat selection by male cerulean warblers (Dendroica cerulea). Auk 123:795-806. doi:10.1642/00048038(2006)123[795:WHUAMS]2.0.CO;2

Bates D (2007) lme4: linear mixed-effects models using S4 classes. R package version 0.99875-9. Cambridge University Press, New York

Berger KM, Gese EM (2007) Does interference competition with wolves limit the distribution and abundance with coyotes? J Anim Ecol 76:1075-1085. doi:10.1111/j.1365-2656.2007.01287.x

Blankenship TL (2000) Ecological response of bobcats to fluctuating prey populations on the Welder Wildlife Foundation Refuge. $\mathrm{PhD}$ thesis. Texas A\&M University, College Station

Brisbin IL Jr., Mowbray TB (2002) American coot (Fulica americana). In: Poole A, Gill F (eds) The birds of North America, vol 697. The Birds of North America, Philadelphia

Burnham KP, Anderson DR (1998) Model selection and multi-model inference: a practical information-theoretic approach. Springer, New York
Choh Y, van der Hammen T, Sabelis MW, Janssen A (2010) Cues of intraguild predators affect the distribution of intraguild prey. Oecologia 163:335-340. doi:10.1007/s00442-010-1605-5

Cooper WE Jr (2000) Tradeoffs between predation risk and feeding in a lizard, the broad-headed skink (Eumeces laticeps). Behaviour 137:1175-1189

Creel S, Christianson D (2008) Relationships between direct predation and risk effects. Trends Ecol Evol 23:194-201. doi: 10.1016/ j.tree.2007.12.004

Creswell W, Lind J, Quinn JL (2010) Predator-hunting success and prey vulnerability: quantifying the spatial scale over which lethal and non-lethal effects of predation occur. J Anim Ecol 79:556562. doi:10.1111/j.1365-2656.2010.01671.x

Crooks KR, Soulé ME (1999) Mesopredator release and avifaunal extinctions in a fragmented system. Nature 400:563-566

Donadio E, Buskirk SW (2006) Diet, morphology, and interspecific killing in carnivora. Am Nat 167:524-536. doi:10.1086/501033

Durant SM (1998) Competition refuges and coexistence: an example from Serengeti carnivores. J Anim Ecol 67:370-386

Fedriani JM, Fuller TK, Sauvajot RM, York EC (2000) Competition and intraguild predation among three sympatric carnivores. Oecologia 125:258-270. doi:10.1007/s004420000448

Fieberg J (2007) Kernel density estimators of home range: smoothing and the autocorrelation red herring. Ecology 88:1059-1066. doi:10.1890/06-0930

Gehrt SD, Prange S (2007) Interference competition between coyotes and raccoons: a test of the mesopredator release hypothesis. Behav Ecol 18:204-214. doi:10.1093/beheco/arl075

Gipson PS, Kamler JF (2002) Bobcat killed by coyote. Southwest Nat 47:511-513

Heilbrun RD, Silvy NJ, Peterson MJ, Tewes ME (2006) Estimating bobcat abundance using automatically triggered cameras. Wildl Soc B 34:69-73

Heithaus MR (2001) Habitat selection by predators and prey in communities with asymmetrical intraguild predation. Oikos 92:542554

Heithaus MR, Dill LM (2002) Food availability and tiger shark predation risk influence bottlenose dolphin habitat use. Ecology 83:480-491. doi:10.1890/0012-9658(2002)083[0480:FAATSP] 2.0.CO;2

Henke SE, Bryant FC (1999) Effects of coyote removal on the faunal community in western Texas. J Wildl Manag 63:1066-1081

Holt RD, Polis GA (1997) A theoretical framework for intraguild predation. Am Nat 149:645-764

Janssen A, Sabelis MW, Magalhães S, Montserrat M, van der Hammen T (2007) Habitat structure affects intraguild predation. Ecology 88:2713-2719. doi:10.1890/06-1408.1

Knick ST (1990) Ecology of bobcats relative to exploitation and prey decline in southeastern Idaho. Wildl Monogr 108:1-42

Lima SL, Dill LM (1990) Behavioral decisions made under the risk of predation: a review and prospectus. Can J Zool 68:619-640

Matter WJ, Mannan RW (2005) How do prey persist? J Wildl Manag 69:1315-1320. doi:10.2193/0022-541X(2005)69[1315:HDPP]2.0. $\mathrm{CO} ; 2$

Mills GLM, Gorman ML (1997) Factors affecting the density and distribution of wild dogs in the Kruger National Park. Conserv Biol 11:1397-1406

Moehrenschlager A, List R, Macdonald DW (2007) Escaping intraguild predation: Mexican kit foxes survive while coyotes and golden eagles kill Canadian swift foxes. J Mammal 88:1029-1039

Mylius SD, Klumpers K, de Roos AM, Persson L (2001) Impact of intraguild predation and stage structure on simple communities along a productivity gradient. Am Nat 158:259-276. doi:10.1086/ 321321

Nams VO (2006) Locate III user's guide. Pacer computer software. Tatamagouche, Nova Scotia 
Neale JCC, Sacks BN (2001) Resource utilization and interspecific relations of sympatric bobcats and coyotes. Oikos 94:236-249

Otteni LC, Bolen EG, Cottam C (1972) Predator-prey relationships and reproduction of the barn owl in southern Texas. Wilson Bull 84:434-448

Palomares F, Caro TM (1999) Interspecific killing among mammalian carnivores. Am Nat 153:492-508

Pettersson LB, Brömark C (1993) Trading off safety against food: state dependent habitat choice and foraging in crucian carp. Oecologia 95:353-357

Plowman BW, Conner LM, Chamberlain MJ, Leopold BD, Burger LW Jr (2006) Annual dynamics of bobcat (Lynx rufus) home range and core use areas in Mississippi. Am Midl Nat 156:386393. doi:10.1674/0003-0031(2006)156[386:ADOBLR]2.0.CO;2

Polis GA, Myers CA, Holt RD (1989) The ecology and evolution of intraguild predation: potential competitors that eat each other. Annu Rev Ecol Syst 20:297-330

Powell RA, Zimmerman JW, Seaman DE (1997) Ecology and behavior of North American black bears: home ranges, habitat, and social organization. Chapman \& Hall, London

R Development Core Team (2008) R: a language and environment for statistical computing. R Foundation for Statistical Computing, Vienna

Randa LA, Cooper DM, Meserve PL, Yunger JA (2009) Prey switching of sympatric canids in response to variable prey abundance. J Mammal 90:594-603

Schabenberger O, Gotway CA (2005) Statistical methods for spatial data analysis. Chapman \& Hall/CRC, Boca Raton

Seaman DE, Millspaugh JJ, Kernohan BJ, Brundige GC, Raedeke KJ, Gitzen RA (1999) Effects of sample size on kernel home range estimates. J Wildl Manag 63:739-747

Sergio F, Marchesi L, Pedrini P (2003) Spatial refugia and the coexistence of a diurnal raptor with its intraguild owl predator. J Anim Ecol 72:232-245. doi:10.1046/j.1365-2656.2003.00693.x

Sergio F, Marchesi L, Pedrini P, Penteriani V (2007) Coexistence of a generalist owl with its intraguild predator: distance-sensitive or habitat-mediated avoidance. Anim Behav 74:1607-1616. doi:10.1016/j.anbehav.2006.10.022

Sih A (1980) Optimal behavior: can foragers balance two conflicting demands? Science 210:1041-1043
Sih A (1992) Prey uncertainty and the balancing of antipredator and feeding needs. Am Nat 139:1052-1069

Sunde P, Bølstad MS, Desfor KB (2003) Diurnal exposure as a risk sensitive behaviour in tawny owls Strix aluco. J Avian Biol 34:409-418. doi:10.1111/j.0908-8857.2003.03105.x

Thompson CM, Gese EM (2007) Food webs and intraguild predation: community interactions of a native mesocarnivore. Ecology 88:334-346. doi:10.1890/0012-9658(2007)88[334:FWAIPC]2.0. $\mathrm{CO} ; 2$

Thornton DH, Sunquist ME, Martin MB (2004) Ecological separation within newly sympatric populations of coyotes and bobcats in south-central Florida. J Mammal 85:973-982

Venable WN, Ripley BD (2002) Modern applied statistics with S, 4th edn. Springer, New York

Ver Hoef JM, Jansen JK (2007) Space-time zero-inflated count models of Harbor seals. Environmetrics 18:697-712. doi:10.1002/ env. 873

Webb JK, Pringle RM, Shine R (2009) Intraguild predation, thermoregulation, and microhabitat selection by snakes. Behav Ecol 20:271-277. doi:10.1093/beheco/arp011

Whitham J, Mathis A (2004) Effects of hunger and predation risk on foraging behavior of graybelly salamanders, Eyrycea multiplicata. J Chem Ecol 26:1559-1561. doi:10.1023/A:10055909 13680

Wilson RR, Hooten MB, Strobel BN, Shivik JA (2010) Accounting for individuals, uncertainty, and multi-scale clustering in core area estimation. J Wildl Manag 74:1343-1352. doi:10.2193/2009-438

Worton BJ (1989) Kernel methods for estimating the utilization distribution in home-range studies. Ecology 70:164-168

Young JK, Andelt WF, Terletzky PA, Shivik JA (2006) A comparison of coyote ecology after 25 years: 1978 versus 2003. Can J Zool $84: 573-582$

Zuberogoitia I, Martínez JE, Zabala J, Martínez JA, Azkona A, Castillo I, Hidalgo S (2008) Social interactions between two owl species sometimes associated with intraguild predation. Ardea 96:109_ 113

Zuur AF, Ieno EN, Walker NJ, Saveliev AA, Smith GM (2009) Mixed effects models and extensions in ecology with R. Springer, New York 